\title{
Partial chaos suppression in a fractional order macroeconomic model
}

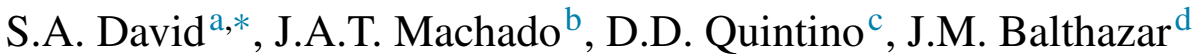 \\ ${ }^{a}$ University of São Paulo at Pirassununga, Av. Duque de Caxias Norte, 225 - 13635-900, Pirassununga, SP, Brazil \\ ${ }^{\mathrm{b}}$ Institute of Engineering, Polytechnic of Porto, Rua Dr. Antonio B. de Almeida 431 - 4249-015, Porto, Portugal \\ ${ }^{\mathrm{c}}$ Federation of Industries of the State of São Paulo, Av. Paulista, 1313 - 01311-923, São Paulo, SP, Brazil \\ ${ }^{\mathrm{d}}$ State University of São Paulo at Rio Claro, Avenida 24 A, 1515-13506-900, Rio Claro, SP, Brazil
}

Received 7 August 2015; received in revised form 18 October 2015; accepted 24 November 2015

Available online 11 December 2015

\begin{abstract}
This work investigates the possibility of suppressing chaos in a fractional-nonlinear macroeconomic dynamic model. The system generalizes a model recently reported in the literature in which chaos is strongly present. This description involves the inclusion of the public sector deficit and its coupling with other variables. The system is simulated for integer and non-integer orders that produce a complex dynamics. The time histories and the phase diagrams are presented. The main contribution of this work refers to the adoption of the largest Lyapunov exponent (LLE) criteria based on Wolf's algorithm. This approach improves the response of the system, suppressing, at least partially, the strong presence of chaos reported in previous studies.

(c) 2015 International Association for Mathematics and Computers in Simulation (IMACS). Published by Elsevier B.V. All rights reserved.
\end{abstract}

Keywords: Macroeconomic model; Fractional calculus; Numerical simulations; Nonlinear systems; Chaos

\section{Introduction}

The dynamics of markets require an accurate modeling for understanding the complex behavior of real world financial and economic systems. A frequent factor in dynamic nonlinear systems is path dependence, so that, the history leading to a supposed level of equilibrium may neither be unique, nor predetermined. This behavior contrasts with the concept of equilibrium in neoclassical economics, in which output presumably reaches equilibrium regardless of its starting point or even in the presence of temporary crisis. In path dependence, the starting conditions, or some noise in the trajectory, can have significant effects on the final outcome, and possibly irreversible consequences.

Studies proposed recently employ fractional derivatives in financial and economic modeling. However, they do not consider the public sector deficit variable in the model and the obtained results indicate a strong presence of chaos.

In this study, we investigate possible impacts resulting from the introduction of an additional variable, namely, the public sector deficit. A fractional differential equation is introduced and their coupling with system dynamic equations is considered. Consequently, one can see how changes in the functional form of the model may lead to different

\footnotetext{
* Corresponding author. Tel.: +55 1935656711 .

E-mail addresses: sergiodavid@usp.br (S.A. David), jtm@isep.ipp.pt (J.A.T. Machado), derick.quintino@ fiesp.org.br (D.D. Quintino), jmbaltha@ rc.unesp.br (J.M. Balthazar).
} 
expansion paths in economics [31]. It is noteworthy that numerous studies about financial-economic markets have been published. However, merely a small part of them use FC as a modeling.

FC can represent systems with high-order dynamics and complex nonlinear phenomena using just a few coefficients, since the arbitrary order of the derivatives provides an additional degree of freedom to fit a specific behavior [26]. In fact, the importance of studies involving nonlinear dynamic and chaos in economic was demonstrated in recent years. This property, allied to the fact that financial-economic variables possess long memories [25], motivated our choice for a more appropriate nonlinear fractional modeling. This paper is organized as follow: in Section 2, we present a brief literature review. In Section 3, we present the fractional order model and several considerations about inclusion of sector public deficit. In Section 4, we consider a sensibility analysis in addition to show and discuss about the numerical simulation results of the fractional order model. Finally, in Section 5 we outline the main concluding comments.

\section{A brief literature review}

Financial and economic variables, such as foreign exchange rates, gross domestic product, interest rates, production, and stock market prices reveal long memory. Indeed, correlations overlap with the longest time scales in the financial-economic market [25,34]. This means that all past fluctuations in financial and economic variables present correlations towards the future. With this fact in mind, FC $[8,10,19,24]$ can be a convenient tool in order to deal with that property. Investigations using FC in financial-economic systems were conducted in [7,12,15,21,20,23,28-30].

Continuous nonlinear and chaotic models that have been proposed to study complex economic dynamics, namely, the forced Van der Pol model [6], the IS-LM (Investment Saving-Liquidity Money) model [3] and others [1,5,13, 14,22,37]. Ma and Chen [17,18] reported an interesting dynamic model of economic system. They found that the model provides irregularity and extreme sensitivity to the initial value of the state and the parameters. Chen [4] considered a generalization of the system proposed in $[17,18]$ for fractional orders. Two typical routes to chaos period doubling and intermittency - were reported. Li and Peng [16] showed a strong presence of chaos in Chen's system with fractional order. However, Chen's model does not consider public sector deficit in the dynamic equations. David et al. [9] proposed a model of fractional order involving the public sector deficit, but the results are inconclusive about the presence (or not) of chaos.

\section{Fractional order macroeconomic model}

In this work, it is considered the public sector deficit $W$ and its coupling with other variables. Furthermore, it is investigated the Largest Lyapunov Exponent (LLE) [2,27] in order to provide an assertive response about the presence of chaotic behavior.

The Lyapunov exponents [11,36] evaluate the sensitive dependence on initial conditions by considering the exponential divergence of nearby orbits. Therefore, one needs to evaluate how trajectories with nearby initial conditions diverge, since they are related to the expanding and contracting nature of different directions in phase space.

The dynamics of the system transform the $D$-sphere of states in to $D$-ellipsoid; therefore, when a chaotic motion emerges, a complex evolution exists. The instabilities are associated with the directions where the stretching occurs, while the stability is associated with the contraction directions.

Mathematically, the Lyapunov exponents consider $d(t)=d_{0} b^{\lambda t}$, where $b$ is a reference basis. In this perspective, the following definition is considered,

$$
\lambda_{i}=\lim _{t \rightarrow \infty}\left(\frac{1}{t} \log _{b}\left(\frac{d_{i}(t)}{d_{0}}\right)\right), \quad i=1,2, \ldots, D,
$$

where $d_{i}(t)$ is the deformed hyper-volume in time instant $t$. The signs of the Lyapunov exponents provide information about the system's dynamics and the greater exponent is an important index to diagnose chaotic motion.

The model adopted here describes the time-variation of four state variables: the interest rate, $X$, the investment demand, $Y$, the price index, $Z$ and the public sector deficit, $W$. The parameters, $a, b, c$ and $d$, are nonnegative, so that $a$ is the saving amount, $b$ is the cost per investment, $c$ is the elasticity of demand of commercial markets and $d$ represents the cost of public debt. 
Fractional order derivatives depend not only on local conditions of the evaluated time, but also on the complete past history of the function. This fact is often useful when the system has a long-term "memory" and any evaluation point depends on the past values of the function. Several studies show empirical subsidies to the discussion on the relation between public deficit, $W$, and others macroeconomic variables. Therefore, we believe to be appropriate to add the variable $W$ and the parameter cost of public debt, $d$, in the model.

We highlight that, as for the problem proposed, we are most concerned with the relationship among the variables and parameters, and their relative influence and capacity of to provoke changes on the system behavior [17,18]. By other words, we are not addressing the absolute amount value of every individual factor in the key structural model. In this line of thought, we consider the following assumptions in the structural model: (i) The factors that influence changes of $X$ mainly come from: the surplus between investment and savings; structure adjustment from the prices of goods; public deficit. Therefore: $\frac{d^{q_{1}} X}{d t^{q_{1}}}=f_{1}(Y-a) X+f_{2} Z+f_{3} W$, where $a, f_{1}, f_{2}$ and $f_{3}$ are constants. (ii) The changing rate of $Y$ is in proportion with the benefit rate of investment, in proportion by inversion with the cost of investment, with the interest rate and with the public deficit, so that, $\frac{d^{q_{2}} Y}{d t^{q_{2}}}=f_{4}\left(\delta-\alpha Y-\beta X^{2}-\gamma W\right)$, where $f_{4}, \delta, \alpha, \beta, \gamma$ are constants. (iii) The factors that influence changes of $Z$ are controlled by the supply and demand and, on the other hand, are influenced by the inflation rate as well as the public deficit. Thus, we write $\frac{d^{q_{3} Z}}{d t^{q_{3}}}=-f_{5} X-f_{6} Z-f_{7} W$, where $f_{5}, f_{6}$ and $f_{7}$ are constants. (iv) The change of $W$ takes into account that it should be proportional to its size. Also, a variation in the interest rate $X$, modifies debt government changing, consequently, the deficit $W$. Assuming that the economy is operating at full employment of its natural output, the public deficit $W$ decreases private investment $Y$. Therefore, we can write $\frac{d^{q 4} W}{d t^{q 4}}=f_{8} W-f_{9} X-f_{10} Y$, where $f_{8}, f_{9}, f_{10}$ are constants.

Nonetheless, by choosing and setting an appropriate dimension to every constant aforementioned and renaming the parameters, we can get the more simplified model. Taking into account these arguments, we proposed a model involving a fractional set of differential equations of arbitrary orders including the public sector deficit $W$, as follows:

$$
\begin{aligned}
& \frac{d^{q_{1}} X}{d t^{q_{1}}}=Z+(Y-a) X+W, \\
& \frac{d^{q_{2}} Y}{d t^{q_{2}}}=1-b Y-X^{2}-W, \\
& \frac{d^{q_{3}} Z}{d t^{q_{3}}}=-X-c Z-W, \\
& \frac{d^{q_{4}} W}{d t^{q_{4}}}=(W-d) X-Y .
\end{aligned}
$$

The public sector deficit $W$ is considered to be financed by the private sector by means of bounds tied to the prime rate; therefore, a rise in the interest rate $X$ raises debt government increasing the deficit $W$, ceteris paribus. Assuming that the economy is operating at full employment of its natural output, the public deficit $W$ decreases the private investment $Y$. This phenomenon is known as crowding-out: the increase in the deficit pressing demand over its capacity, that causes a rise in interest rates $X$ to suppress the economy growth; however, the rise in interest rates discourages private investment $Y$. The interest rate $X$ has a considerable importance in defining the level of the investments $Y$, since it directly impacts upon this variable. Ceteris paribus, a rise in the level of interest rate $X$ tends towards reducing investments $Y$, resulting in the growth of opportunity cost of capital. The increase in interest rate, $X$, reduces the present value of future flows of income that the investment, $Y$, can bring. Regarding the increase in the price index $Z$, modern Central Banks use interest rates $X$ as a basic instrument to ensure a better control in prices dynamics. The increases in interest rates, $X$, tend to reduce consumption by making credit costs more expensive, therefore stimulating the formation of savings from private sector.

With these facts in mind, and adopting macroeconomic system (2), several numerical simulations are performed in the sequel for integer and non-integer orders of the derivatives. It is well known that there are various definitions of fractional derivatives $[19,24]$. In this study, we apply the Riemann-Liouville approach and the Adams scheme in order to proceed with the numerical simulations of the fractional derivatives. Briefly, the Riemann-Liouville approach can be understood from the definition of integration of arbitrary order:

$$
\frac{d^{m}}{d x^{m}}\left[{ }_{c} D_{x}^{-\rho} f(x)\right]=\frac{d^{m}}{d x^{m}}\left[\frac{1}{\Gamma(\rho)} \int_{c}^{x}(x-t)^{\rho-1} f(t) d t\right] .
$$


Table 1

Cases and range values of order $\alpha$.

\begin{tabular}{llll}
\hline Case & Order & Range of values of $\alpha$ & Parameters $(\delta ; \sigma ; \varphi)$ \\
\hline I & $q_{1}=q_{2}=q_{3}=q_{4}=\alpha$ & $0.40 \leq \alpha \leq 1.0$ & $(4 ; 25 ; 0.6)$ \\
II & $q_{2}=q_{3}=q_{4}=1$ and $q_{1}=\alpha$ & $0.40 \leq \alpha \leq 1.0$ & $(4 ; 85 ; 2)$ \\
III & $q_{1}=q_{3}=q_{4}=1$ and $q_{2}=\alpha$ & $0.40 \leq \alpha \leq 1.0$ & $(4 ; 80 ; 0.4)$ \\
IV & $q_{1}=q_{2}=q_{4}=1$ and $q_{3}=\alpha$ & $0.20 \leq \alpha \leq 1.0$ & $(4 ; 73 ; 0.6)$ \\
V & $q_{1}=q_{2}=q_{3}=1$ and $q_{4}=\alpha$ & $0.20 \leq \alpha \leq 1.0$ & $(4 ; 12 ; 0.6)$ \\
\hline
\end{tabular}
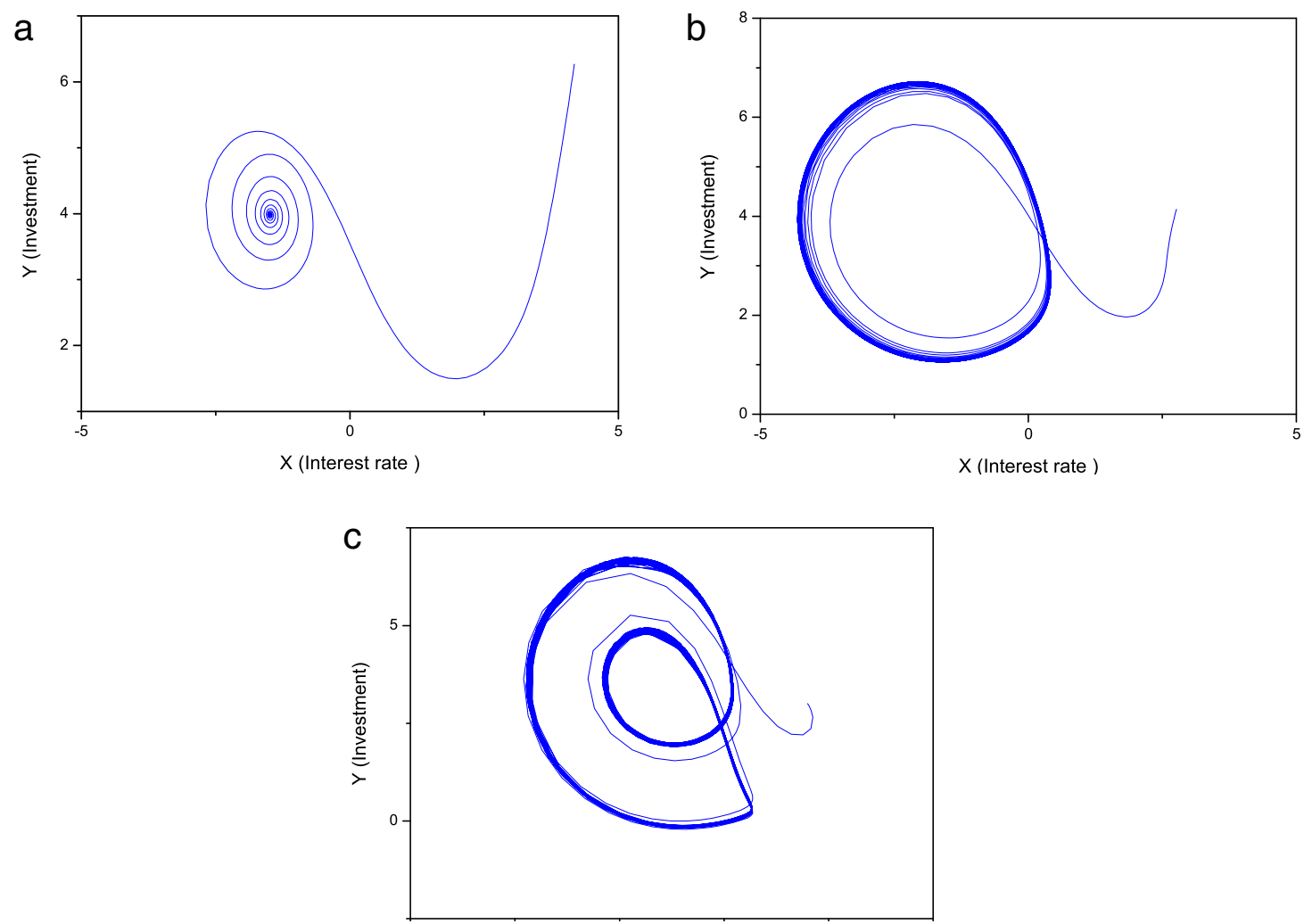

Fig. 1. State $X-Y$ for system (2) with fractional order $q_{1}=q_{2}=q_{3}=q_{4}=\alpha$, (a) $\alpha=0.84$, (c) $\alpha=0.93$, (f) $\alpha=1.0$.

More details about the Riemann-Liouville approach and the Adams numerical integration scheme can be found in $[8,33]$.

\section{Results and discussion}

In this section several numerical simulations explore the advantages of the proposed model. We present the range of values for the derivative orders and the responses are shown and discussed. The results reveal some kind of chaos suppression when compared with previous studies.

It is also well known that the sensibility analysis adjusts the variables and observes their influence up on the system. Swamy et al. [32] show that it is possible to estimate the direct effect of an independent variable upon a dependent variable, with all of its other determinants held constant, even in the presence of an unknown functional form, measurement error and omitted variables. However, we have several variables and, if they are studied one by one, then the sensibility analysis becomes difficult and time-consuming to perform. In order to improve the efficiency of the analysis, we propose a first round of simulation considering $\alpha=q_{1}, q_{2} q_{3}, q_{4}$ (i.e., the derivatives of arbitrary 

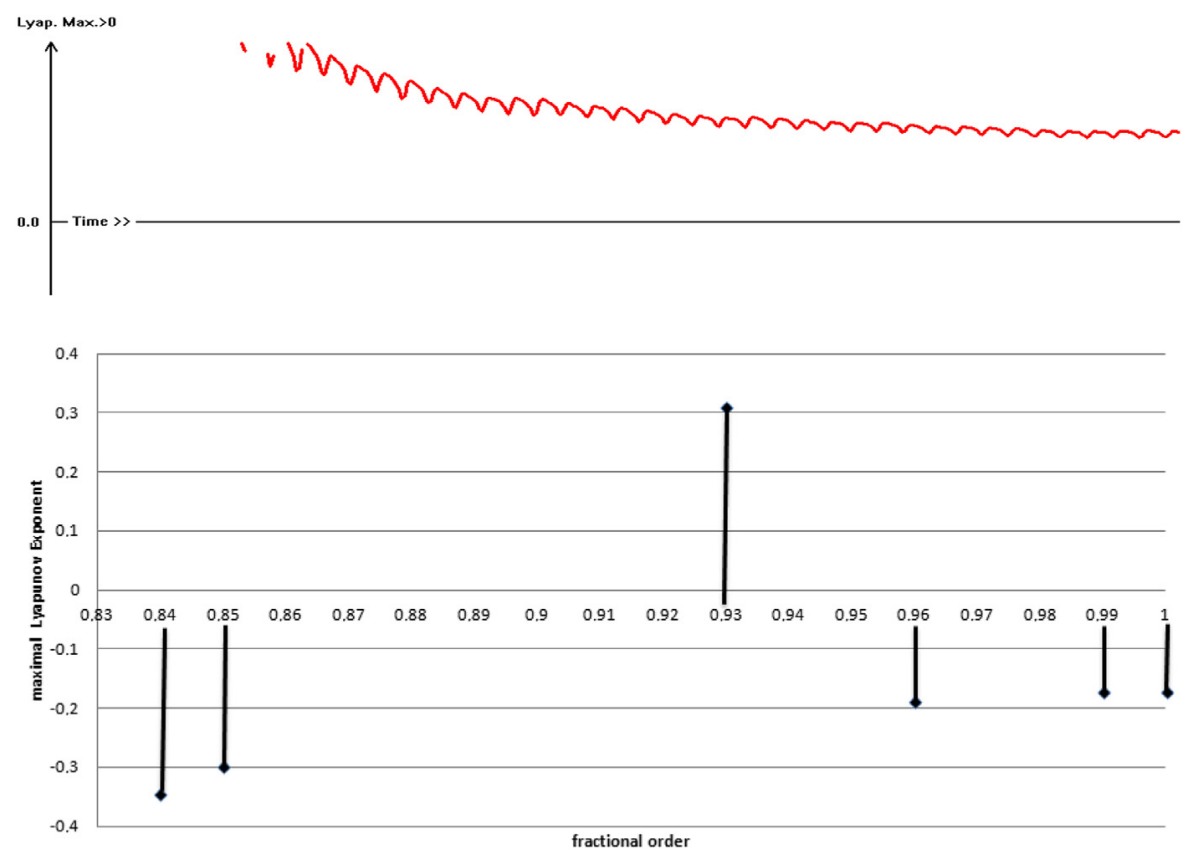

Fig. 2. Largest Lyapunov Exponent (LLE) - Case I $-q_{1}=q_{2}=q_{3}=q_{4}=\alpha$.
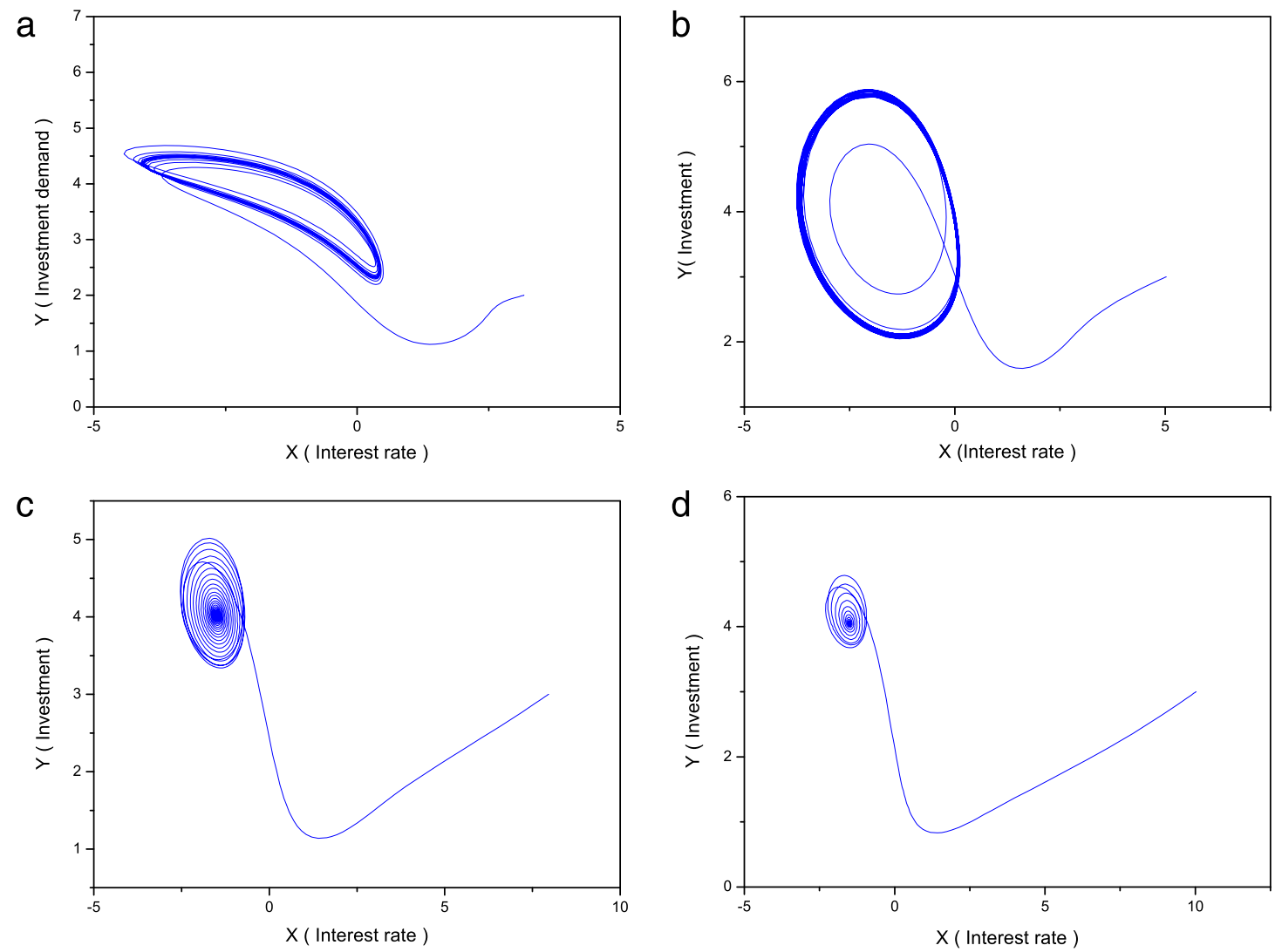

Fig. 3. State $X-Y$ for system (2) with fractional order $q_{2}=q_{3}=q_{4}=1$ and $q_{1}=\alpha$, (a) $\alpha=0.90$, (b) $\alpha=0.80$, (c) $\alpha=0.70$, (d) $\alpha=0.65$. 

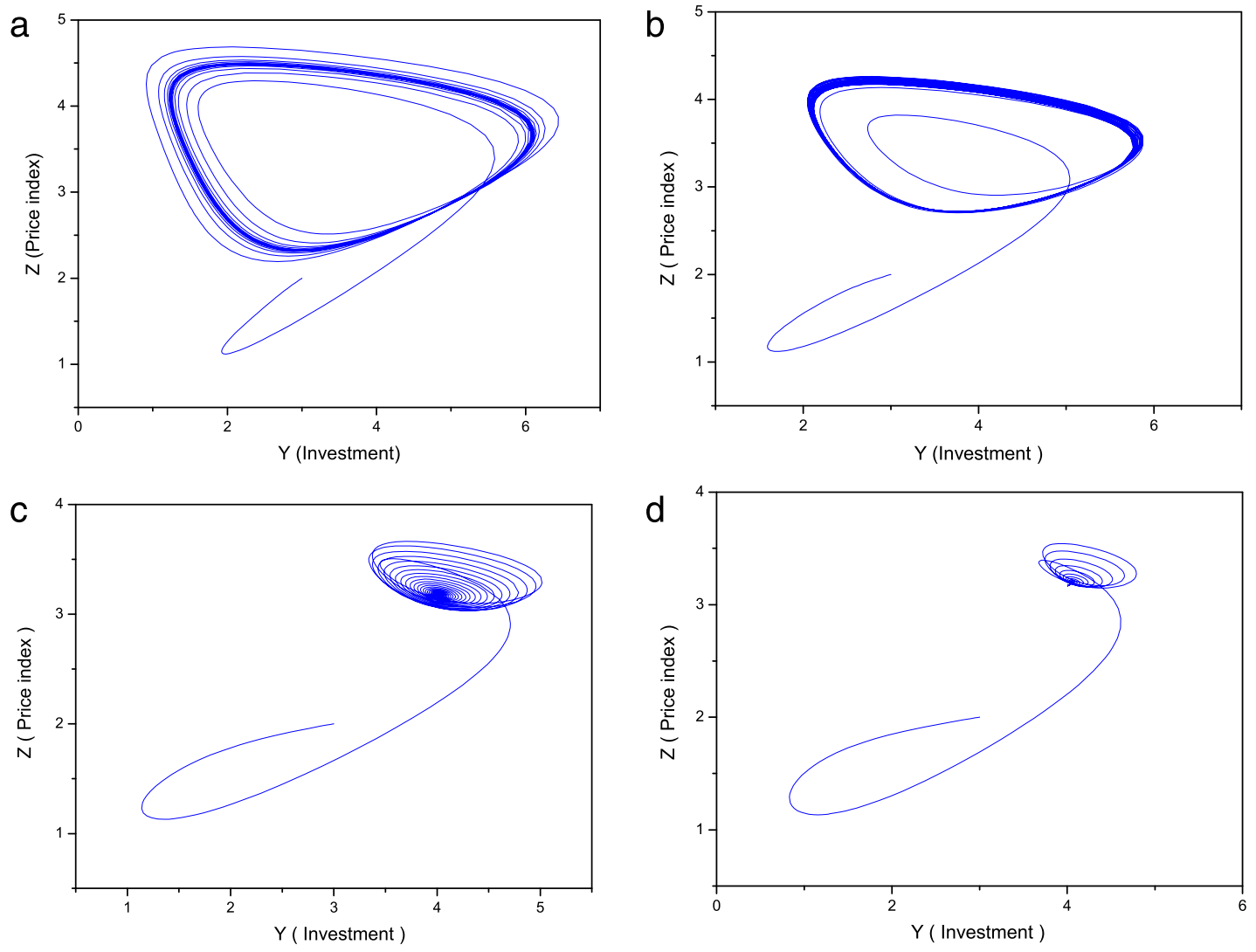

Fig. 4. State $Y-Z$ for system (2) with fractional order $q_{2}=q_{3}=q_{4}=1$ and $q_{1}=\alpha$, (a) $\alpha=0.90$, (b) $\alpha=0.80$, (c) $\alpha=0.70$, (d) $\alpha=0.65$.
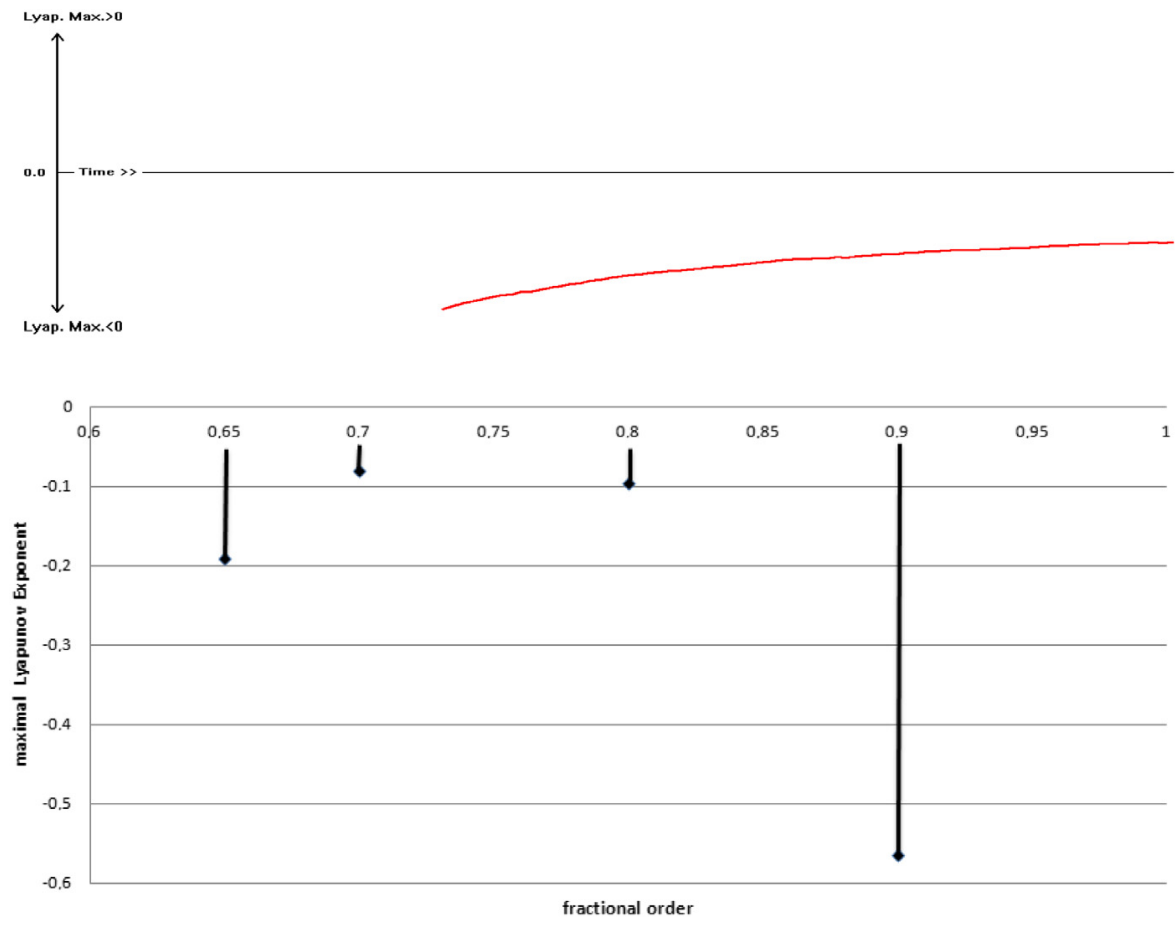

Fig. 5. Largest Lyapunov Exponent (LLE) - Case II $-q_{2}=q_{3}=q_{4}=1$ and $q_{1}=\alpha$. 

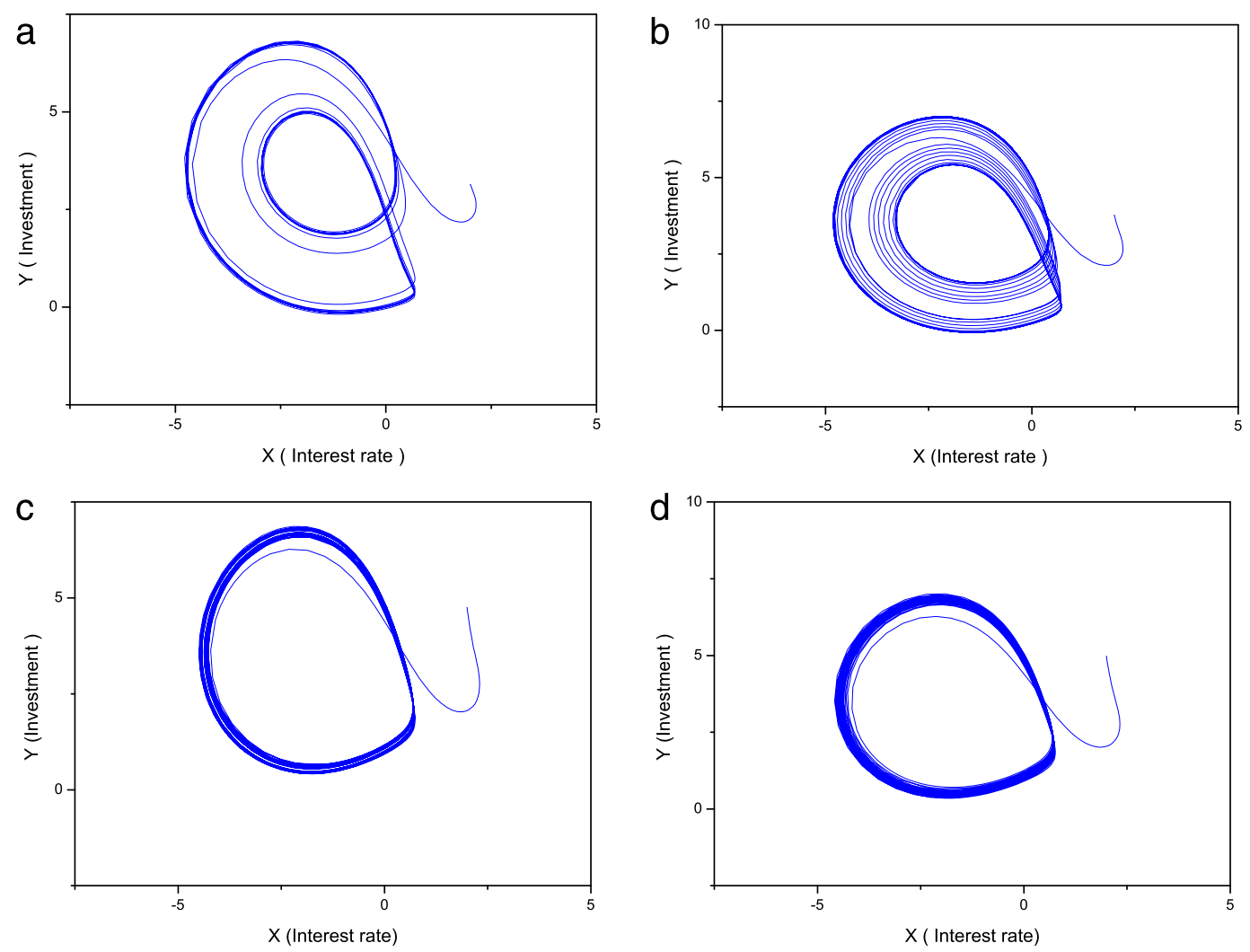

Fig. 6. State $X-Y$ for system (2) with fractional order $q_{1}=q_{3}=q_{4}=1$ and $q_{2}=\alpha$, (a) $\alpha=0.99$, (b) $\alpha=0.95$, (c) $\alpha=0.90$, (d) $\alpha=0.89$.

orders in system (2)) and a finite interval of the variation of the order $\alpha$. Table 1 shows the cases to be investigated in this work and the range of values of $\alpha$ adopted in the numerical simulations.

The system is simulated using both integer and fractional orders. In order to compare our results with the values reported by Chen [4], we consider the following parameters: $a=3.0, b=0.1, c=1.0$ and $d=1.0$, with the initial state $\left(X_{0}, Y_{0}, Z_{0}, W_{0}\right)=(2.0,3.0,2.0,1.0)$. The time histories, phase diagrams and (LLE) criteria are adopted to identify the system. The figures are chosen in order to allow a comparison with other works previously referenced.

Using the Runge Kutta solver and the Largest Lyapunov Exponent (LLE) criteria based on Wolf's algorithm $[35,36]$, we find that chaos exist in the nonlinear fractional-order model. However, in our model, including the public sector deficit $W$, we verify that chaos occurs less frequently when compared to Chen's model. We outline that LLE is investigated for the range of values of $\alpha$ and the LLE is calculated for each one of the cases listed in Table 1. The other parameters adopted in the numerical simulations, namely, embedding dimension $(\delta)$, the embedding delay $(\sigma)$ and the maximal initial distance $(\varphi)$ are also listed in Table 1. For all other points, there is no information indicative of occurrence of chaos. Nevertheless, for the sake of comparison, we also show the LLE obtained for the same values of $\alpha$ reported by Chen [4].

Case I-Commensurate orders $q_{1}=q_{2}=q_{3}=q_{4}=\alpha$

System (2) is simulated numerically for $\alpha \in[0.40,1]$. Note that (2) corresponds to the integer-order system, when $\alpha=1$. The state plots of $X$ (Interest rate) $-Y$ (Investment) are depicted in Fig. 1(a)-(c). The trajectory for $\alpha=0.84$ is attracted to a fixed point when $t \rightarrow+\infty$ indicating stability. For $\alpha=0.93$ and $\alpha=1$ we can note limit cycles. Fig. 2 indicates the presence of chaos for a single value of the fractional order, namely, $\alpha=0.93$ and $\lambda_{\text {máx. }}=0.308$.

Case II-orders $q_{2}=q_{3}=q_{4}=1$ and $q_{1}=\alpha$

System (2) is simulated against $\alpha \in[0.40,1]$. Figs. 3(a)-(d) and 4(a)-(d) show the diagrams of $X$ (Interest rate) $Y$ (Investment) and $Y$ (Investment) $-Z$ (Price index), respectively, for $\alpha=0.90, \alpha=0.80, \alpha=0.70$ and $\alpha=0.65$. Limit cycles occur for Fig. 3(a) and (b) and for Fig. 4(a) and (b). Moreover, Fig. 3(c) and (d) and Fig. 4(c) and (d) show that the trajectories converge to a fixed point when $t \rightarrow+\infty$, indicating stability. The results presented in Fig. 5 

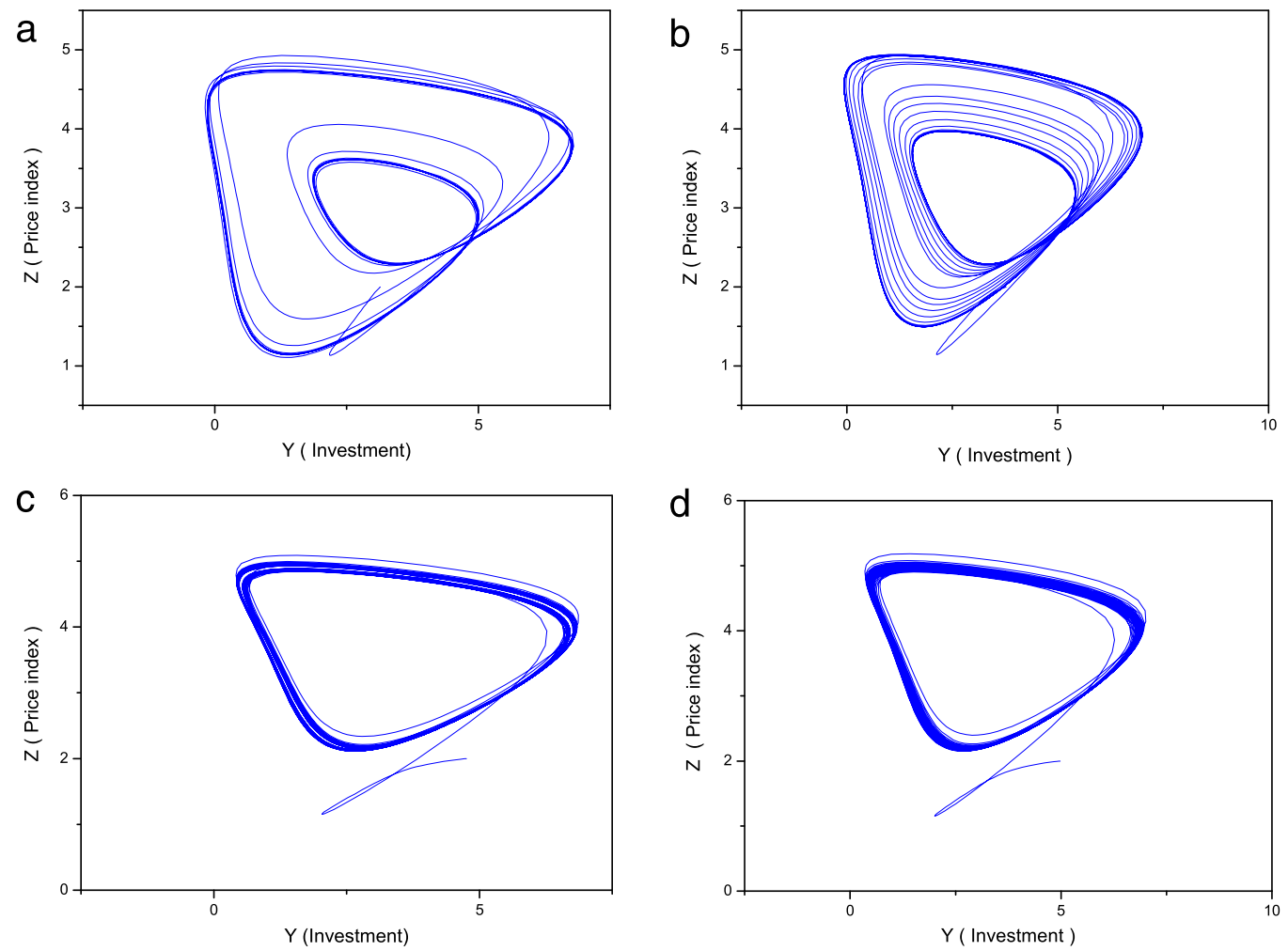

Fig. 7. State $Y-Z$ for system (2) with fractional at $q_{1}=q_{3}=q_{4}=1$ and $q_{2}=\alpha$, (a) $\alpha=0.99$, (b) $\alpha=0.95$, (c) $\alpha=0.90$, (d) $\alpha=0.89$.
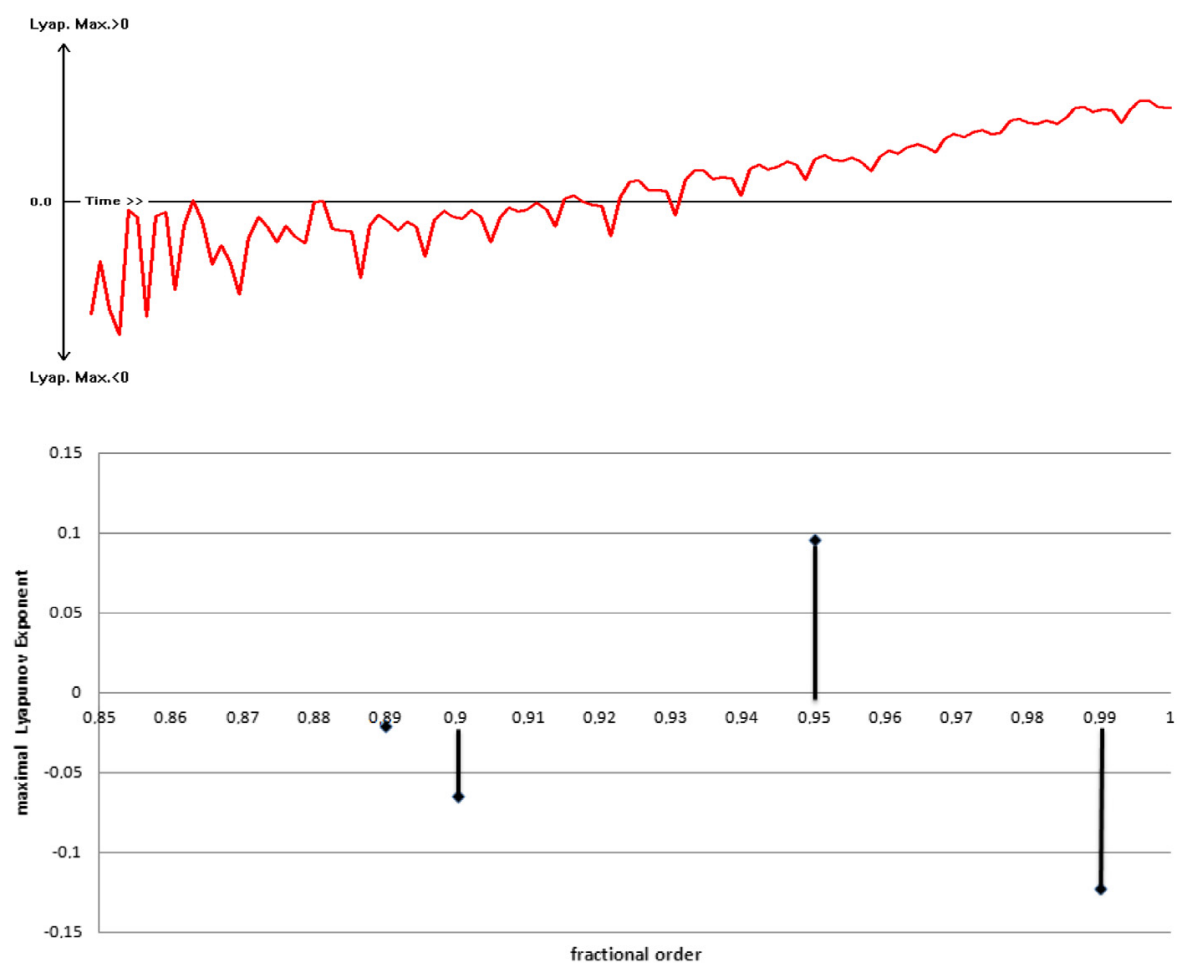

Fig. 8. Largest Lyapunov Exponent (LLE) - Case III $-q_{1}=q_{3}=q_{4}=1$ and $q_{2}=\alpha$. 

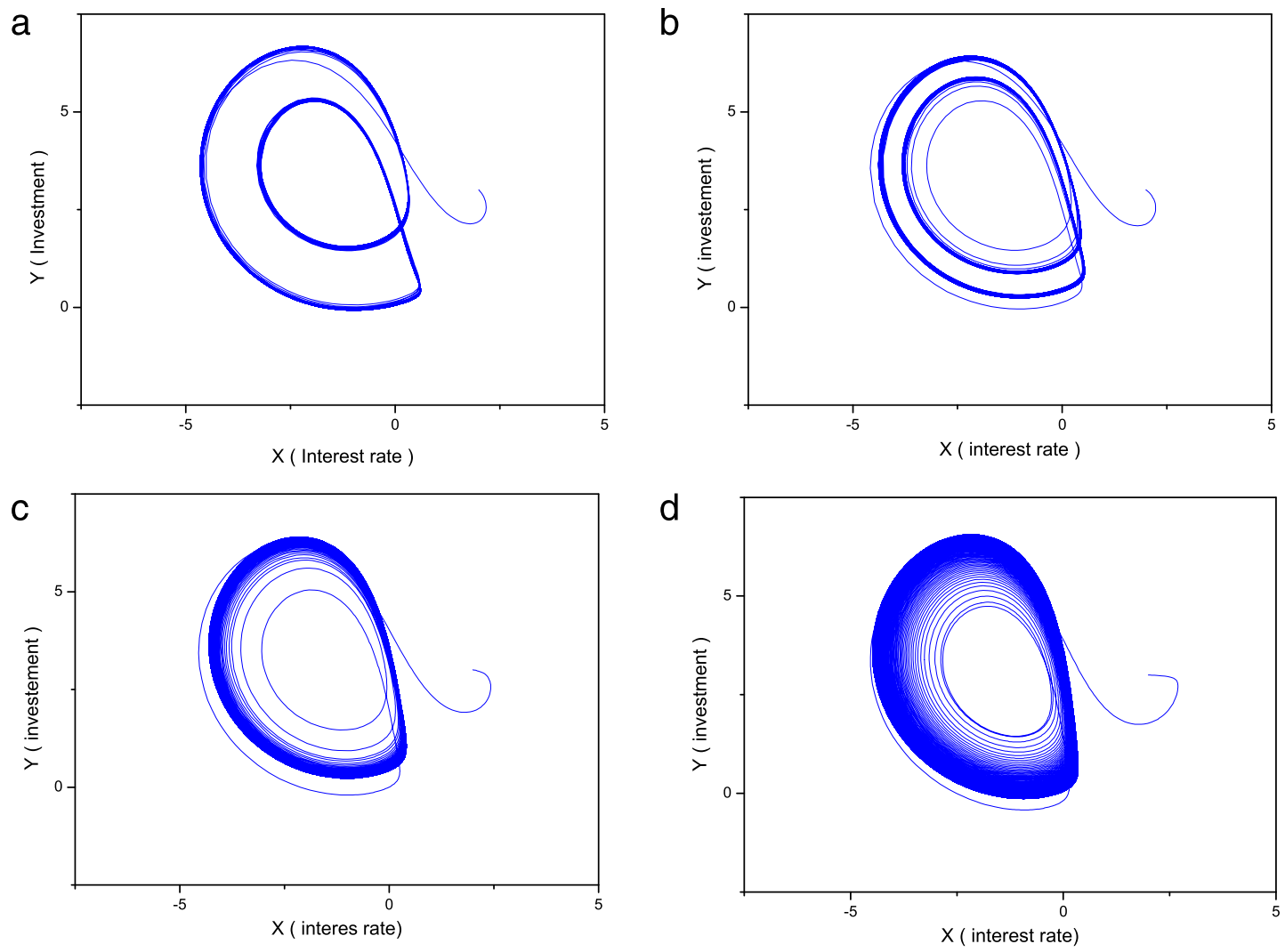

Fig. 9. State $X-Y$ for system (2) with fractional order $q_{1}=q_{2}=q_{4}=1$ and $q_{3}=\alpha$, (a) $\alpha=0.90$, (b) $\alpha=0.80$, (c) $\alpha=0.50$, (d) $\alpha=0.20$.

do not show evidence, and are not indicative of, chaotic behavior for our model within the $\alpha$ range investigated and that $\lambda_{\text {máx. }}=-0.081$.

Case III-orders $q_{1}=q_{3}=q_{4}=1$ and $q_{2}=\alpha$

In this case, the system is simulated against $\alpha \in[0.40,1]$. The time evolution consists of oscillations that appear to be regular and showing no intermittency. Chen [4] reported intermittency in the time histories of $X$ (Interest rate) for $\alpha=0.89,0.891,0.893,0.895$. Figs. 6(a)-(d) and 7(a)-(d) show the phase diagrams of $X$ (Interest rate) $-Y$ (Investment) and $Y$ (Investment) $-Z$ (Price index) respectively for $\alpha=0.99, \alpha=0.95, \alpha=0.90$ and $\alpha=0.89$. We can observe the limit cycles suggesting orbital stability. Fig. 8 indicates the presence of chaos for a single value of the fractional order, $\alpha=0.95$ and $\lambda_{\text {máx. }}=0.096$.

Case IV-orders and $q_{1}=q_{2}=q_{4}=1$ and $q_{3}=\alpha$

System (2) is simulated for $\alpha \in[0.20,1]$. Figs. 9(a)-(d) and 10(a)-(d) show the phase diagrams of $X$ (Interest rate) $-Y$ (Investment) and $Y$ (Investment) $-Z$ (Price index) respectively for $\alpha=0.90, \alpha=0.80$, and $\alpha=0.50$ and $\alpha=0.20$. Again, we can observe the limit cycles indicating orbital stability. One can notice that, Fig. 11 shows chaotic behavior for all values of indicated and the LLE occurs in $\alpha=0.90$ and $\lambda_{\text {máx. }}=0.247$.

Case V-orders $q_{1}=q_{2}=q_{3}=1$ and $q_{4}=\alpha$

In this case V, system (2) is simulated numerically for $\alpha \in[0.20,1]$. Figs. 12 and 13 show the limit cycles obtained. Fig. 14 indicates the presence of chaos for a single value of the fractional order, namely, $\alpha=0.84$ and $\lambda_{\text {máx. }}=0.434$.

The periodic behaviors in these cases correspond to a stable cycle as reflected by the periodic oscillations. The increase or decrease of the values of $\alpha$ does not lead to period doubling or to any interruption of the regular behaviors of oscillations. However, we outline that the results obtained by applying the LLE criteria, as shown in the aforementioned figures, reveal chaotic behaviors for some cases in our model. Figs. 2, 8 and 14 indicate the presence of chaos for a single value of the fractional order, namely, $\alpha=0.93, \alpha=0.95$ and $\alpha=0.84$, respectively. One can also notice that Fig. 11 shows chaotic behavior for all values of $\alpha$ investigated. On the other hand, the results 

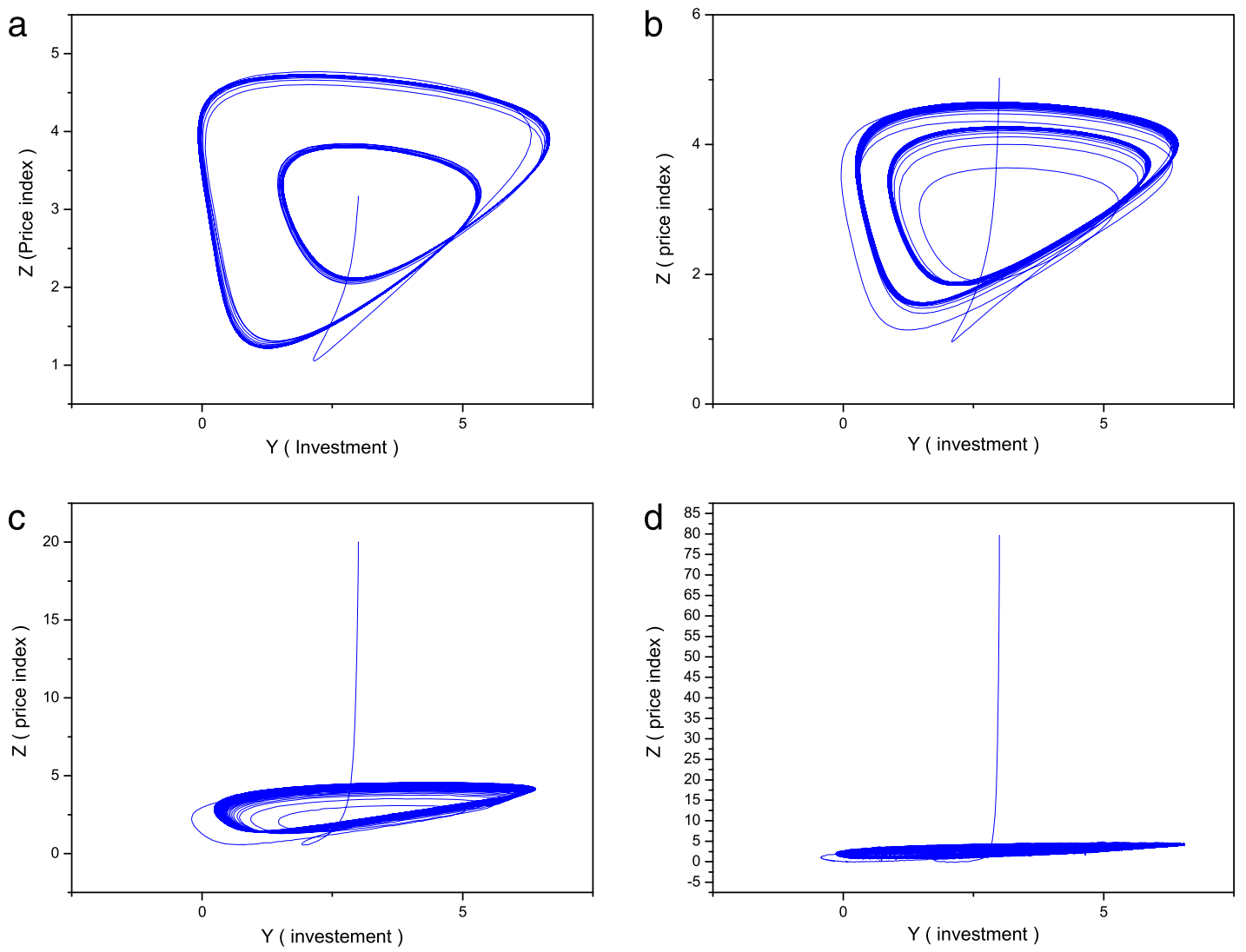

Fig. 10. State $Y-Z$ for system (2) with fractional $q_{1}=q_{2}=q_{4}=1$ and $q_{3}=\alpha$, (a) $\alpha=0.90$, (b) $\alpha=0.80$, (c) $\alpha=0.50$, (d) $\alpha=0.20$.
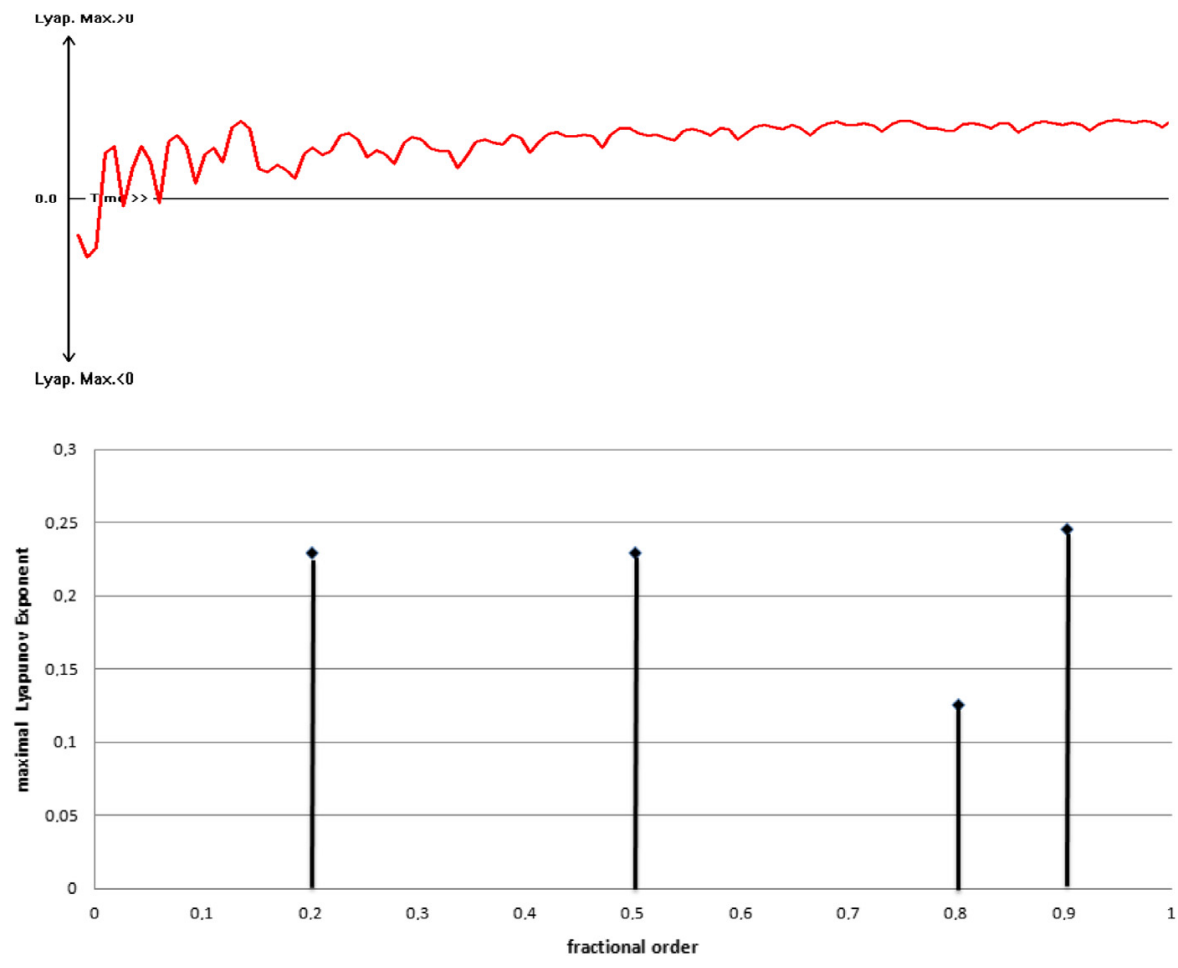

Fig. 11. Largest Lyapunov Exponent (LLE) - Case IV $-q_{1}=q_{2}=q_{4}=1$ and $q_{3}=\alpha$. 

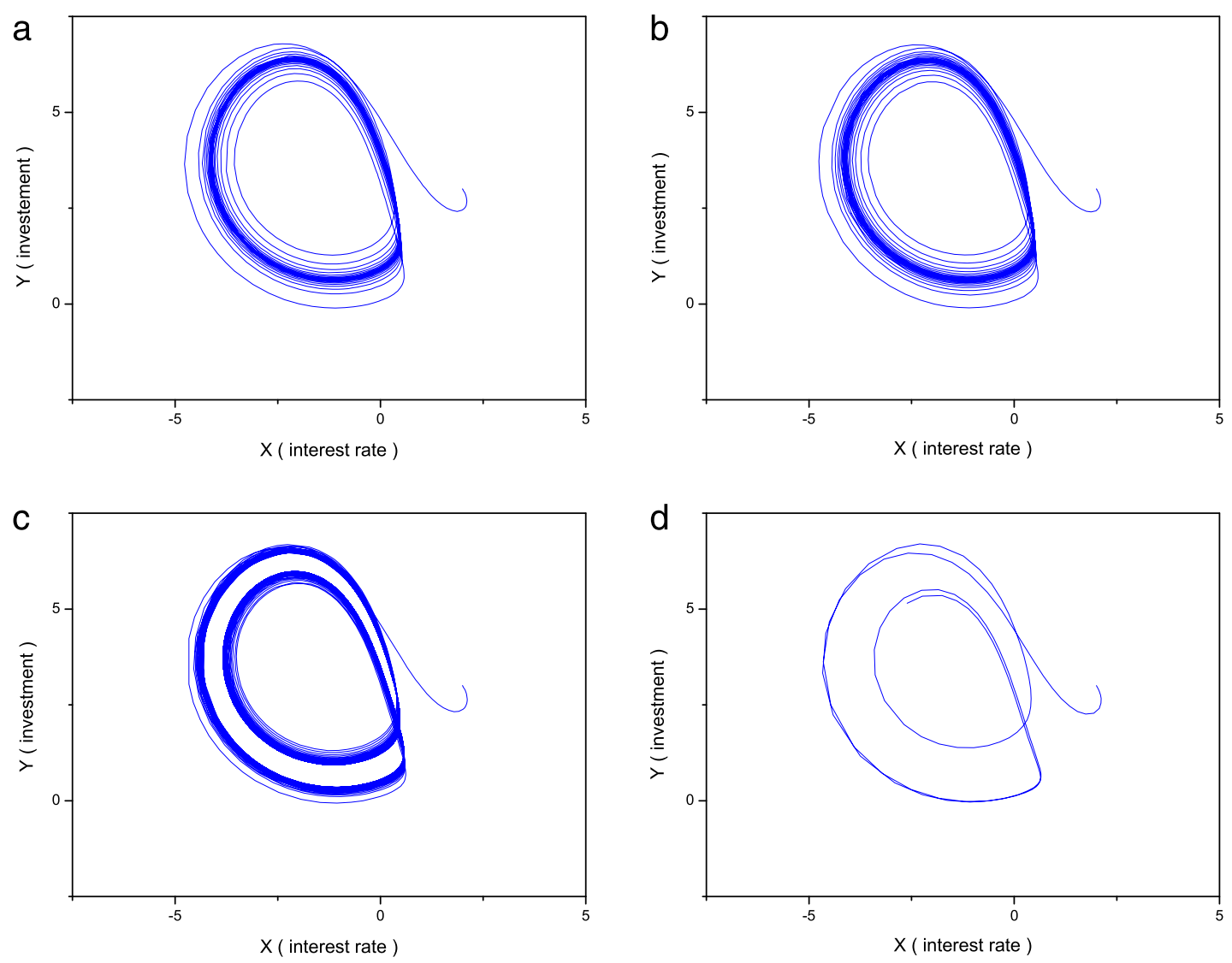

Fig. 12. State $X-Y$ for system (2) with fractional $q_{1}=q_{2}=q_{3}=1$ and $q_{4}=\alpha$, (a) $\alpha=0.95$, (b) $\alpha=0.90$, (c) $\alpha=0.84$, (d) $\alpha=0.83$.

Table 2

Results comparison.

\begin{tabular}{llll}
\hline Case & $\begin{array}{l}\text { Range of values of } \alpha \\
\text { Investigated }\end{array}$ & $\begin{array}{l}\text { W.C. Chen (2008) } \\
\text { (chaos reported) }\end{array}$ & $\begin{array}{l}\text { Current paper } \\
\text { (occurrence of chaos) }\end{array}$ \\
\hline I & $0.40 \leq \alpha \leq 1.0$ & $0.85 \leq \alpha \leq 1.0$ & $\alpha=0.93$ \\
II & $0.40 \leq \alpha \leq 1.0$ & $0.69 \leq \alpha \leq 1.0$ & Chaos not found \\
III & $0.40 \leq \alpha \leq 1.0$ & $0.90 \leq \alpha \leq 1.0$ & $\alpha=0.95$ \\
IV & $0.20 \leq \alpha \leq 1.0$ & $\alpha=0.35 ; 0.50 ; 0.83 \leq \alpha \leq 0.9$ & $\alpha=0.20 ; 0.50 ; 0.80 ; 0.90$ \\
V & $0.20 \leq \alpha \leq 1.0$ & Not available & 0.84
\end{tabular}

a Absence of the public deficit (W) and of the $q_{4}$ variable derivative order in Chen's model.

presented in Fig. 5 do not show evidence, and are not indicative of, chaotic behavior for our model within the $\alpha$ range investigated. Table 2 provides a summary of the main results and allows a comparison between the results obtained by Chen [4] and the new ones.

\section{Conclusions}

Fractional models are appropriate for financial-economic systems because they reveal long memory effects. The model treated here is a generalization of a dynamic model recently reported and involves the public sector deficit equation, which renders the description more realistic and complete when compared with those proposed previously. We highlight that our numerical simulations take into account this renewed model with the inclusion of the public sector deficit. The results show an improvement in its behavior because they suppress, at least partially, the presence of chaos reported in other studies in the current literature. Additionally, this work adopts the Largest Lyapunov Exponent 
66

S.A. David et al. / Mathematics and Computers in Simulation 122 (2016) 55-68
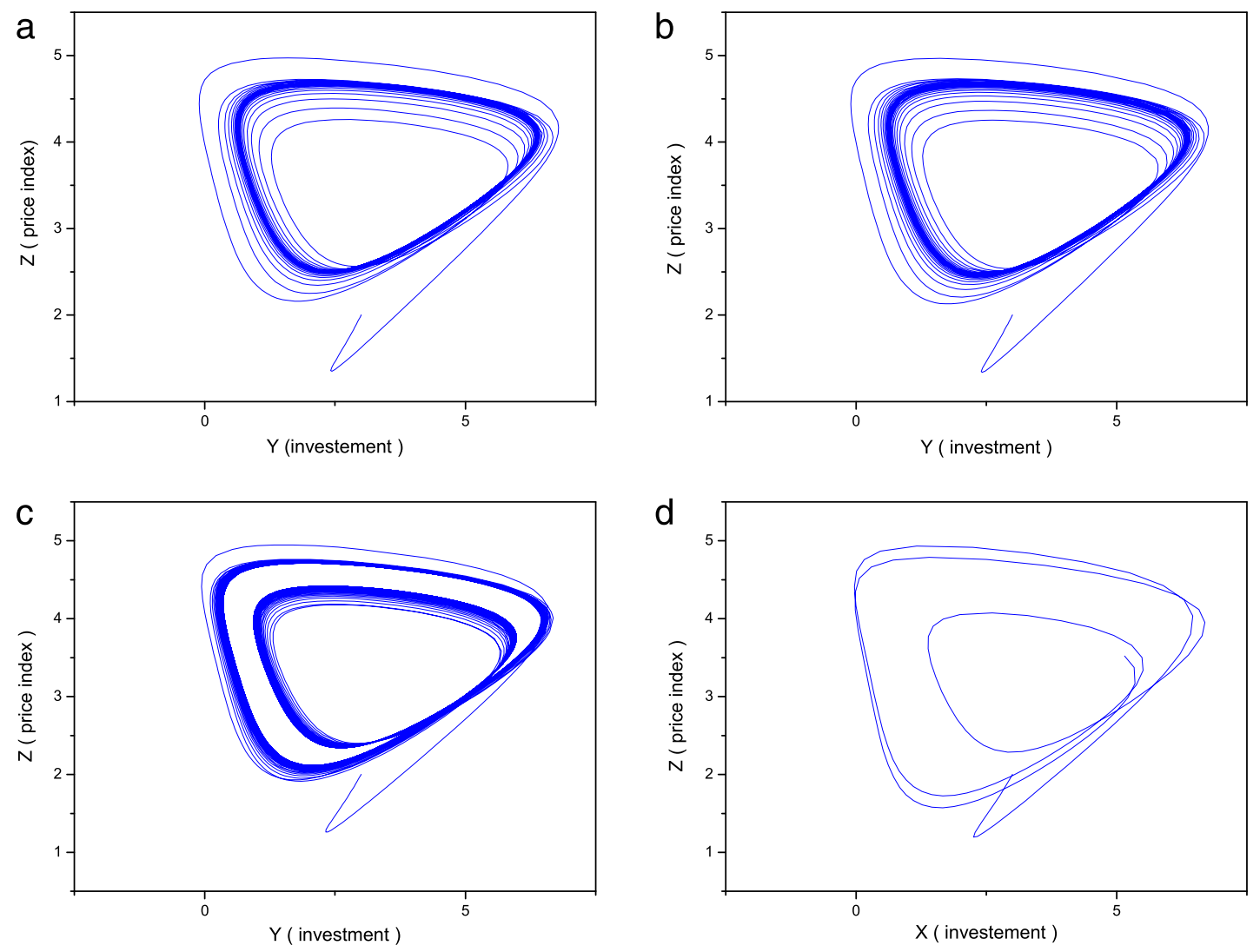

Fig. 13. State $Y-Z$ for system (2) with fractional $q_{1}=q_{2}=q_{3}=1$ and $q_{4}=\alpha$, (a) $\alpha=0.95$, (b) $\alpha=0.90$, (c) $\alpha=0.84$, (d) $\alpha=0.83$.
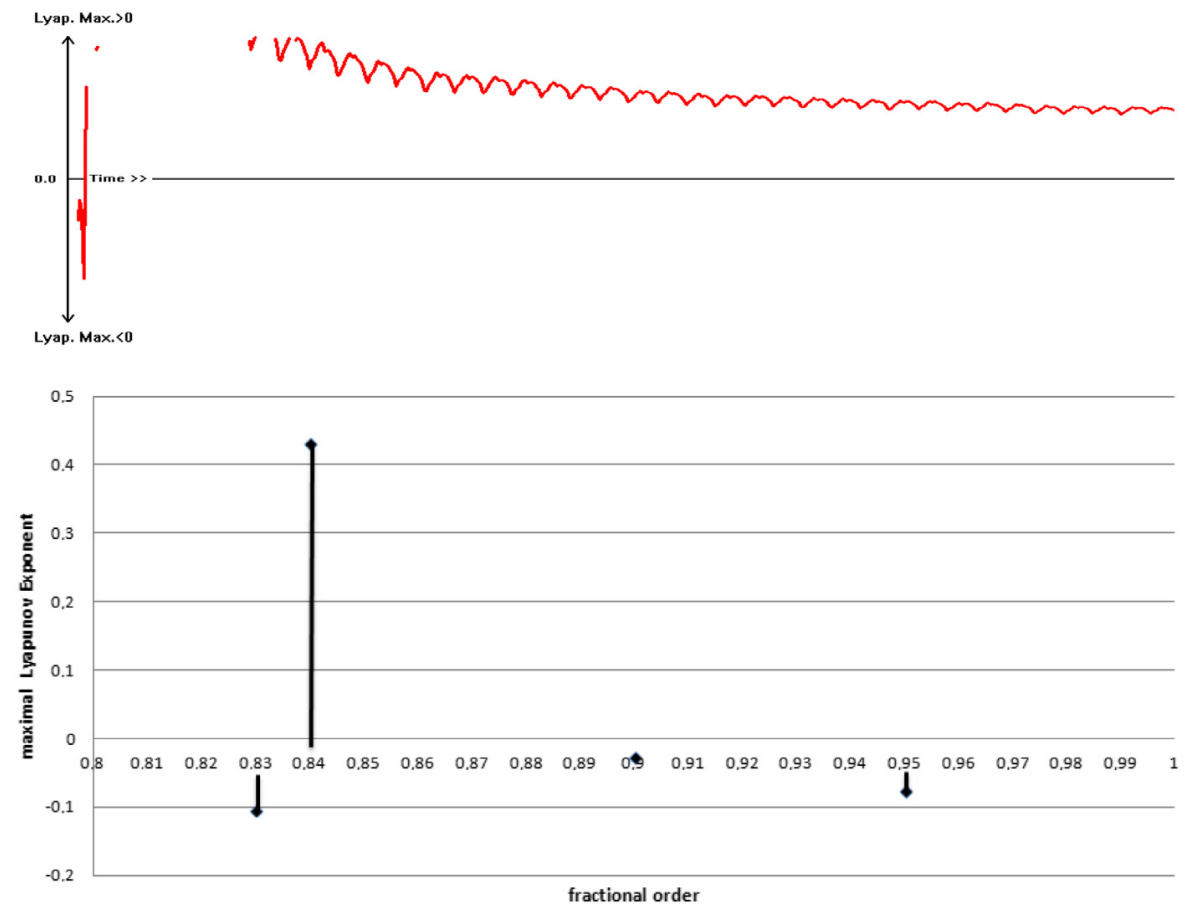

Fig. 14. Largest Lyapunov Exponent (LLE) - Case V $-q_{1}=q_{2}=q_{3}=1$ and $q_{4}=\alpha$. 
in order to provide an assertive response about the presence (or not) of chaotic behavior for the fractional-nonlinear macroeconomic dynamic model.

\section{Acknowledgments}

The authors wish to acknowledge the FAPESP (São Paulo Research Foundation, grant 2010/15824-0 and grant 2014/02041-9) for funding support. The authors are also grateful to B.H.S. Julio and J. Y. Soliani by the partial contribution in numerical simulations.

\section{References}

[1] W.A. Barnett, A.R. Gallant, M.J. Hinich, J.A. Jungeilges, D.T. Kaplan, M.J. Jensen, A single-blind controlled competition among tests for nonlinearity and chaos, J. Econometrics 82 (1) (1997) 157-192.

[2] M. Bask, R. Gençay, Testing chaotic dynamics via Lyapunov exponents, Phys. D 114 (1998) 261-266.

[3] L.D. Cesare, M.A. Sportelli, A dynamic IS-LM model with delayed taxation revenues, Chaos Solitons Fractals 25 (2005) $233-244$.

[4] W.C. Chen, Nonlinear dynamics and chaos in a fractional-order financial system, Chaos Solitons Fractals 36 (2008) $1305-1314$.

[5] L. Chen, G. Chen, Controlling chaos in a economic model, Phys. A 374 (1) (2007) 349-358.

[6] A.C.L. Chian, Nonlinear dynamics and chaos in macroeconomics, Int. J. Theor. Appl. Finance 3 (2000) 601.

[7] S.A. David, in: B. A. Wade et al. (Eds.), Computational and Math. Methods in Sci. and Eng., Chicago, ISBN:978-84-690-6886-8, 2007, pp. $148-158$.

[8] S.A. David, J.L. Linares, E.M.J.A. Pallone, Fractional order calculus: historical apologia, basic concepts and some applications, Rev. Bras. Ensino Fís. 33 (4) (2011) http://dx.doi.org/10.1590/S1806-11172011000400002.

[9] S.A. David, D.D. Quintino, J. Soliani, Fractional order in a macroeconomic dynamic model, AIP Conf. Proc. 1558 (2013) http://dx.doi.org/ 10.1063/1.4825961.

[10] E.C. De Oliveira, J.A.T. Machado, A review of definitions for fractional derivatives and integral, Math. Probl. Eng. (2014) http://dx.doi.org/ $10.1155 / 2014 / 238459$.

[11] L.F.P. Franca, M.A. Savi, in: J.M. Balthazar, et al. (Eds.), 2002, Nonlinear Dynamics, Chaos, Control and Their Application to Eng. Sciences, in: Chaos, Control and Time Series, ISBN: 85-900351-5-8, 2000, pp. 325-334.

[12] R. Gorenflo, F. Mainardi, E. Scalas, M. Raberto, Fractional calculus and continuous-time finance III: the diffusion limit, Math. Finance (2001) $171-180$.

[13] D.A. Hsieh, Chaos and nonlinear dynamic: application to financial markets, J. Finance 46 (5) (1991) 1839-1877.

[14] S. Invernizzi, A. Medio, On lags and chaos in economic dynamic models, J. Math. Econom. 20 (6) (1991) 521-550.

[15] N. Laskin, Fractional market dynamics, Physica A 287 (2000) 482-492.

[16] C. Li, G. Peng, Chaos in Chen's system with a fractional order, Chaos Solitons Fractals 22 (2004) 443-450.

[17] J.H. Ma, Y.S. Chen, Study for the bifurcation topological structure and the global complicated character of a kind of nonlinear finance system (I), Appl. Math. Mech. (English Ed.) 22 (2001) 1240-1251.

[18] J.H. Ma, Y.S. Chen, Study for the bifurcation topological structure and the global complicated character of a kind of nonlinear finance system (II), Appl. Math. Mech. (English Ed.) 22 (2001) 1375-1382.

[19] J.A.T. Machado, V. Kiryakova, F. Mainardi, Recent history of fractional calculus, Commun. Nonlinear Sci. Numer. Simul. 16 (3) (2011) 1140-1153.

[20] J.A.T. Machado, M.E. Mata, A fractional perspective to the bond graph modeling of world economies, Nonlinear Dynam. (2014) http://dx.doi.org/10.1007/s11071-014-1334-0.

[21] J.A.T. Machado, M.E. Mata, Pseudo phase plane and fractional calculus modeling of western global economic downturn, Commun. Nonlinear Sci. Numer. Simul. (2014) http://dx.doi.org/10.1016/j.cnsn.2014.08.032.

[22] J.A.T. Machado, M.E Mata, Analysis of world economic variables using multidimensional scaling, PLoS One 10 (3) (2015) http://dx.doi.org/ 10.1371/journal.pone.0121277.

[23] M.M. Meerschaert, E. Scalas, Coupled continuous time random walks in finance, Phys. A 370 (1) (2006) 114-118.

[24] K.B. Oldham, J. Spanier, The Fractional Calculus: Theory and Applications of Differentiation and Integration to Arbitrary Order, Dover Publication, New York, 2006.

[25] E. Panas, Long memory and chaotic models of price on the London metal exchange, Res. Policy 27 (2001) $235-246$.

[26] I. Podlubny, Fractional Differential Equations, Academic Press, New York, 1999.

[27] M.T. Rosenstein, J.J. Collins, C.J. De Luca, A practical method for calculating largest Lyapunov exponents from small data sets, Physica D 65 (1993) 117-134.

[28] E. Scalas, The application of continuous-time random walks in finance and economics, Phys. A 362 (2) (2006) $225-239$.

[29] E. Scalas, R. Gorenflo, F. Mainardi, Fractional calculus and continuous time finance, Physica A 284 (1) (2000) 376-384.

[30] E. Scalas, R. Gorenflo, F. Mainardi, Fractional calculus and continuous time finance II: the waiting-time distributon, Phys. A 287 (3) (2000) 468-481.

[31] R. Shone, Econ. Dynamics, Cambridge University Press, Cambridge, 2002.

[32] P.A.V.B. Swamy, G. Tavlas, S.G.F. Hall, G. Hondroyiannis, Estimation of parameters in the presence of model misspecification and measurement error, Stud. Nonlinear Dyn. Econom. 14 (3) (2010) 1-32.

[33] D. Valerio, J.J. Trujillo, M. Rivero, J.A.T. Machado, D. Baleanu, Fractional calculus: a survey of useful formulas, Eur. Phys. J. Spec. Top. 222 (2013) 1827-1846. http://dx.doi.org/10.1140/epjst/e2013-01967-y. 
[34] B.J. Wes, S. Picozzi, Fractional langevin model of memory in financial time series, Phys. Rev. E 66 (2002) http://dx.doi.org/10.1103/ PhysRevE.66.046118.

[35] A. Wolf, Quantifying chaos with Lyapunov exponents, Chaos (1986) 273-290.

[36] A. Wolf, J.B. Swift, H.L. Swinney, J.A. Vastano, Determining Lyapunov exponents from a time series, Physica D 16 (1985) $285-317$.

[37] W. Wu, Z. Chen, W.H. Ip, Complex nonlinear dynamics and controlling chaos in a Cournot duopoly economic model, Nonlinear Anal. RWA 11 (5) (2010) 4363-4377. 